\title{
An application of multiple satellite data and GIS to management of fisheries resources
}

KATSUYA SAITOH ${ }^{1,2}$, SEI-ICHI SAITOH ${ }^{1}$ AND HIDEO TAMEISHI ${ }^{2}$

1 Graduate School of fisheries Science, Hokkaido University, 3-1-1 Minatocyo Hakodate, Hokkaido,041-8661,Japna, and ${ }^{2} J a p a n$ Fisheries Information service Center 4-5 Toyomi, Cyuo-ka, Tokyo 140-0055,Japan (ksaitoh@jafic.or.jp)

SUMMARY: In 1996, Japanese Fisheries Agency started management of fisheries resource by TAC (Total allowable catch). The management of the fisheries resource is an important issue. In this research, it was tried to elucidate the change of the fish resource by using the satellite data. The study fish is a sardine. Sardine resource around Japan repeats a big increasing and decreasing. Sardines catch volume increased rapidly in 80's, and decreased sharply in 90's. The change trend of an oceanic environment of the Touhoku sea area was presumed according to this multi satellite data at the period. The trend of the water temperature presumed from the satellite rose. On the other hand, the trend of Chlorophyll-a presumed from the satellite was descending. The data of the water temperature and Chlorophyll-a presumed the satellite was compared with the data of the sardine resource. As a result, a positive correlation was confirmed between Chlorophyll-a and the sardine resource of Oyashio water and perturbed water. On the other hand, a negative correlation was confirmed between the water temperature and the sardine resource.

KEYWORDS: Satellite, Remote sensing, Sardine resource, Multi sensor, GIS,

\section{INTRODUCTION}

The management of the fisheries resource is an important issue. In 1996, Japanese Fisheries Agency started management of fisheries resource by TAC. TAC is decided $\mathrm{ABC}$ (Available Biological Catch.). To estimate $\mathrm{ABC}$ accurately, it is very important. In this research, The study fish is a sardine. Sardine resource changes greatly (Fig.1). Many kind of research try to analyze this big changes ${ }^{1)}$.

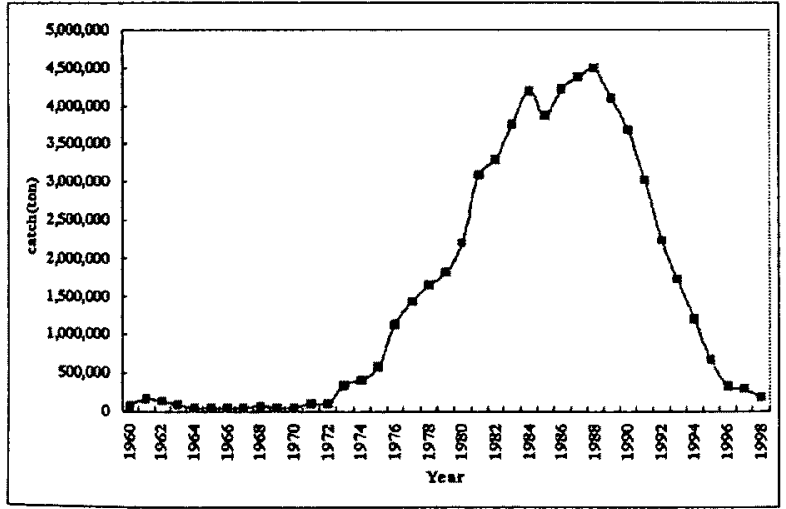

Fig.1 Catch histories of sardine in Japan.

The satellite remote sensing data is a useful data for fisheries. Satellite has two special features. There are Wide area observation and measure many times. Additionally, long-term data is made a data base. The objective of this research is to elucidate the change of the fish resource by using the satellite data. The trend of the water temperature and Chlorophyll-a was calculated first. As a result, a long-term change of an oceanic environment of the
Touhoku sea area is considered. In addition, data of the sardine resource and oceanic environmental data are compared.

\section{STUDY AREA}

Fig. 2 shows study area. The water is hydrographically divided into three in this study area. These are Kuroshio Area, Perturbed Area and Oyashio Area. This area is important for many kind of fish. There is sardine's migration area.

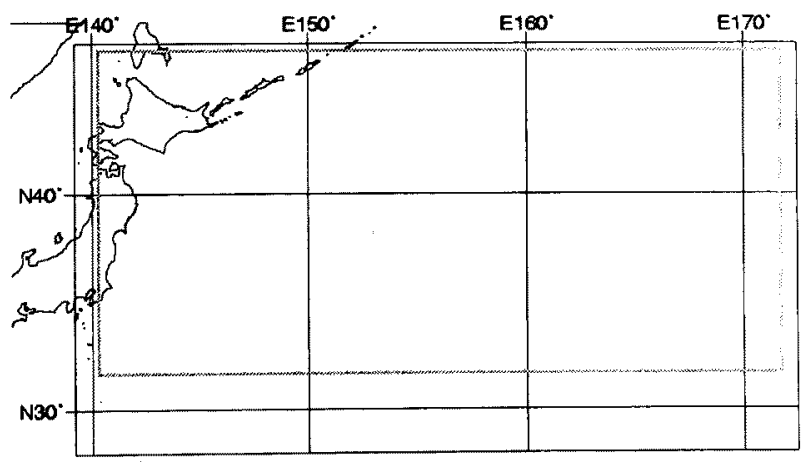

Fig.2 Study area.

\section{DATA AND METHODS}

MCSST data is observed by NOAA-AVHRR from 1981 to 2000 . This data is created by NASA/DAAC ${ }^{2}$. Satellite Chlorophyll-a data is multi satellite observed by Nimbus7/CZCS, ADEOS/OCTS, and Seastar/SeaWiFS. CZCS data is processed by NASA/DAAC. OCTS data is processed by NASA/GSFC and SeaWiFS data processed 
processed by NASA/GSFC and SeaWiFS data processed by $\mathrm{NASA}^{3)}$. Fisheries data was collected from annual report of JFA, NRIFS report, and FAO report ${ }^{1 / 4)}$. Fig.3 shows a data processing flow of this study. The point of this process is to create vector data and create database. Vector data elements are year, month, latitude, longitude, and physical value.

Table.1 Satellite dataset

\begin{tabular}{lll} 
Object & Satellite and Sensor & Period \\
\hline MCSST & NOAA/AVHRR & $1981 / 11-2000 / 12$ \\
Pigment & NImbus7/CZCS & $1978 / 12-1986 / 6$ \\
chlorophyll a & ADEOS/OCTS & $1996 / 11-1997 / 6$ \\
& Seastar/SeaWiffS & $1997 / 8-2000 / 12$
\end{tabular}

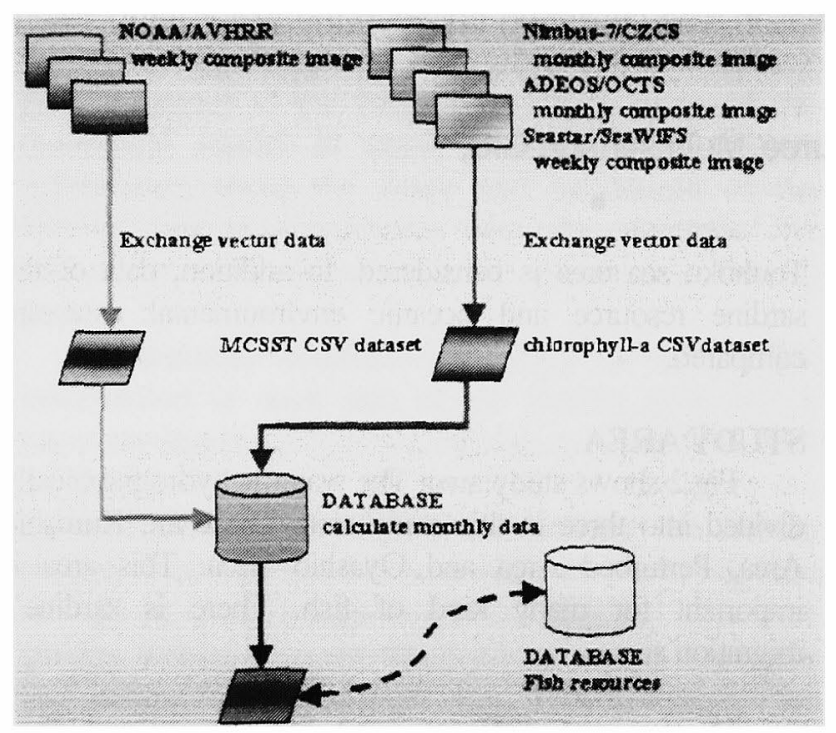

Fig.3 Data processing

\section{Water mass classification}

Kawai (1972) proposes the index water temperature of Oyashio, the index water temperature of Kuroshio is proposed, and the index water temperature of warm water. In this research, the position of the index water temperature was calculated from the water temperature data of JAFIC. The number of processed data is about 350,000 points. As a result, the position of Oyashio became $41-42^{\circ}$ north. Moreover, the position of Kuroshio became $34-36^{\circ}$ north. Fig. 2 shows the result. The position of the index water temperature changes by the season and the year. However, an average position was as showing in Fig.2. In this research, this north latitude was assumed to be a standard of the water mass classification.

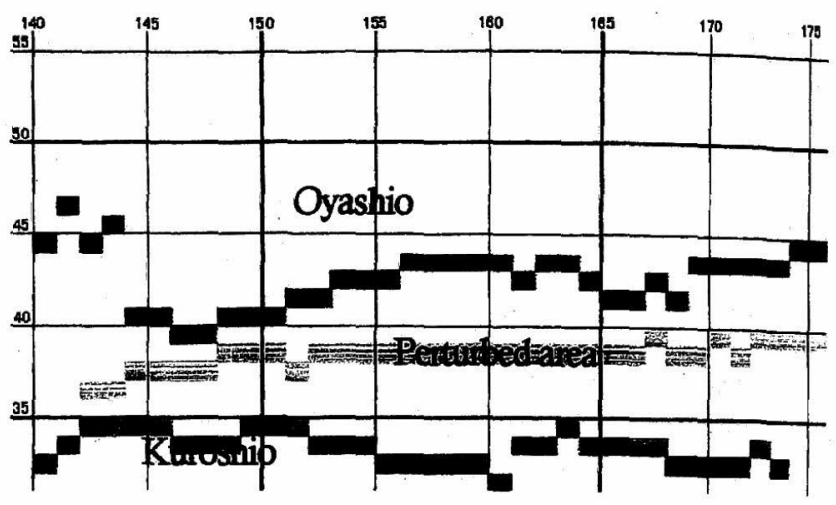

Fig.4 Time series of Index temperature position MAP (X-axis is Lat. $\mathrm{Y}$-axis is Long.) Marker shown Oyashio index (upper), position, warm water index (middle), Kuroshio index (Low)

\section{MCSST TREND}

Fig. 5 shows the time series of the Kuroshio water temperature. The trend of the Kuroshio water temperature rises. Fig.6 shows the water temperature time series of Perturbed area. This water mass's water temperature trend rose, too. Rising level was stronger than other water masses. Fig.7 shows the time series of the Oyashio water temperature. The trend of the water temperature rose. Any water mass showed rising trend in the water temperature of the Touhoku region.

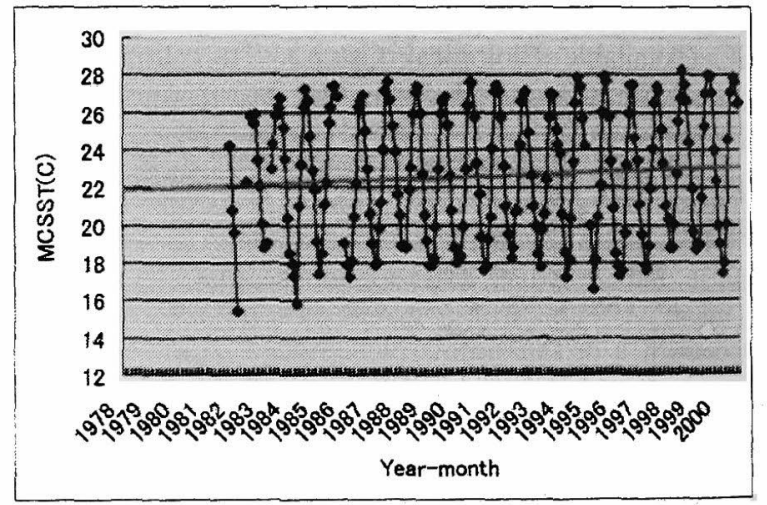

Fig.5 Long-term change and trend about MCSST (Kuroshio area).

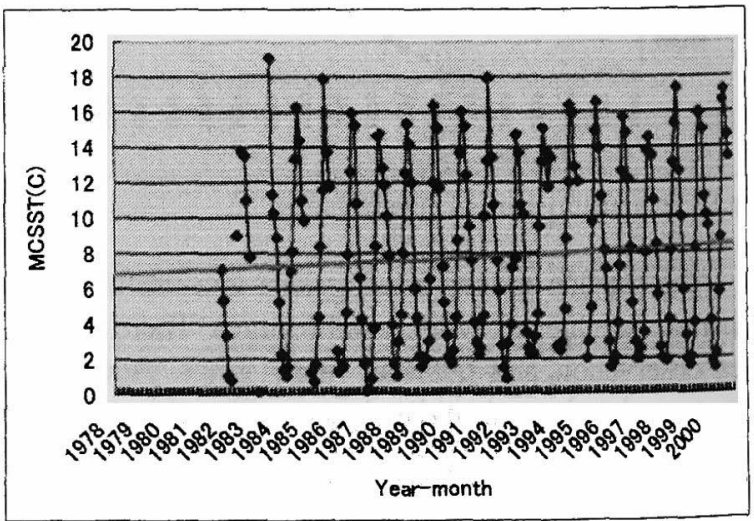

Fig. 6 Long-term change and trend about MCSST (Perturbed area). 


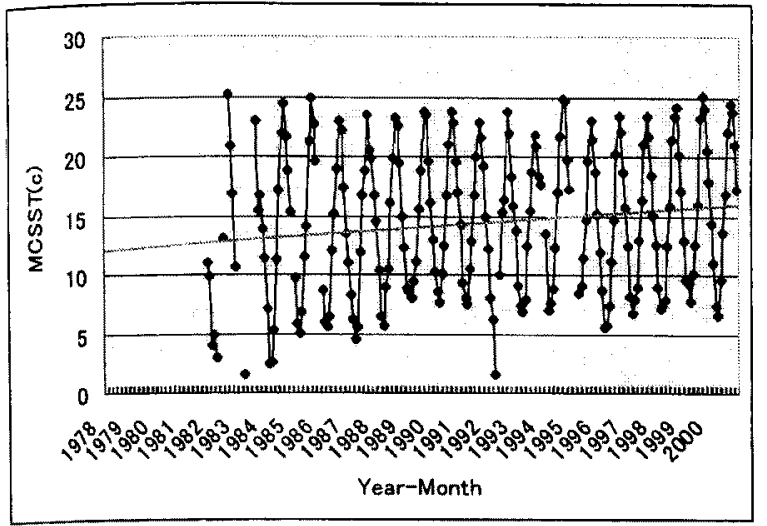

Fig.7 Long-term change and trend about MCSST (Oyashio area).

\section{CHLOROPHYLLAA TREND}

Fig.6 shows the time series of Chlorophyll-a of Kuroshio. The trend of Chlorophyll-a of Kuroshio does not have a big change. Fig.6 is seen rising trend. However, the change in the absolute value of Y-axis is small. Fig.7 shows the time series of Chlorophyll-a of Perturbed area. This water mass's trend is descending. Fig.8 shows the time series of Chlorophyll-a of Oyashio. This trend was similarly descending, too. Chlorophyll-a in the Touhoku region roughly showed the descent trend.

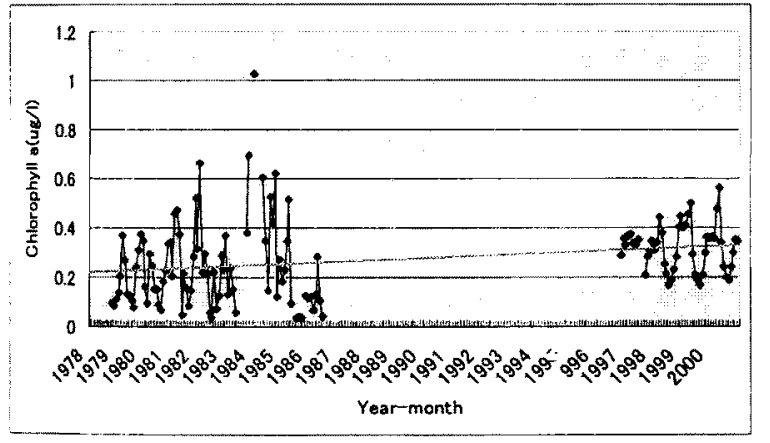

Fig. 8 Long-term change and trend about Chlorophyll-a (Kuroshio area).

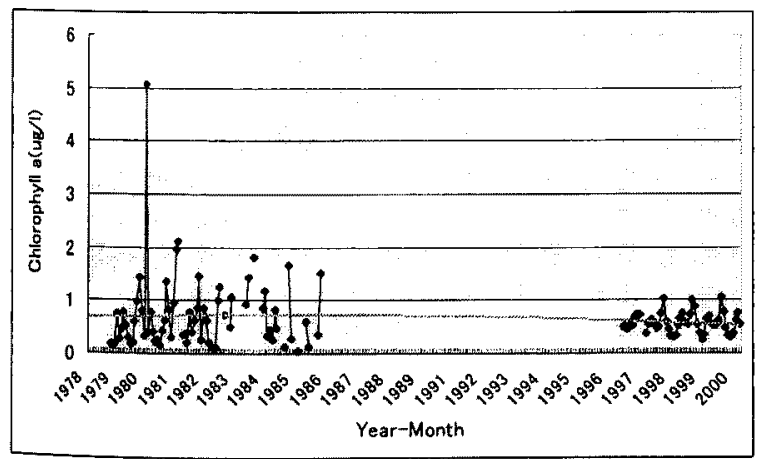

Fig.9 Long-term change and trend about Chlorophyll-a (Perturbed area)..

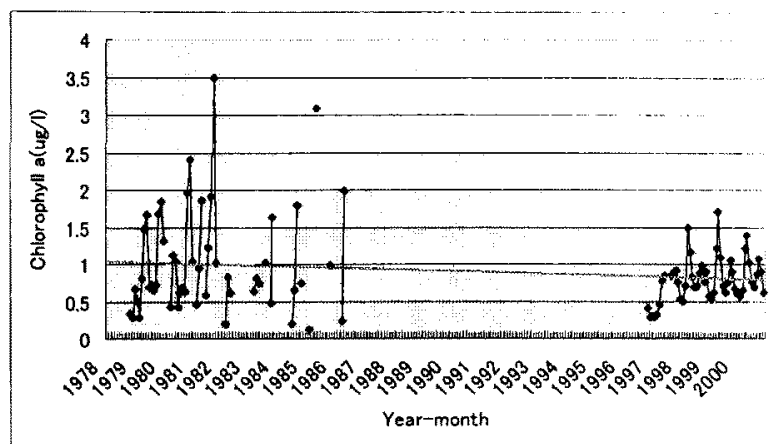

Fig.10 Long-term change trend about Chlorophyll-a (Oyashio area)..

\section{RELATION BETWEEN SARDINE RESOURCE AND OCEANIC ENVIRONMENT IN TOHOKU AREAR}

Wada (1998) estimates sardine's resource. Moreover, NRIFS (National Research Institute of Fisheries in Japan) estimates the resource to presume $A B C$ every year. The oceanic environmental data presumed from this data and the satellite was compared. The resource data are SSB and recruitment. Fig.9 shows Recruitment and the Perturbed area water temperature relation. Fig.10 shows the relation to SSB. Fig.11 shows the relation between Recruitment and Chlorophyll-a (Perturbed area). Fig.12 shows the relation between SSB and Chlorophyll-a. In all figures, the line is oceanic environments (MCSST or Chlorophyll-a). Moreover, box shows Recruitment or SSB. Oceanic environmental data of Oyashio and oceanic environmental data of Kuroshio were compared with the resource data. As a result of statistical data processing, the correlation coefficient of the environment and the resource was very low values as for all sea areas. The correlation of Chlorophyll-a was better than that of the water temperature. Chlorophyll-a and the resource of Oyashio and Perturbed area were positive correlations. However, Chlorophyll-a and the sardine resource in Kuroshio were negative correlations. All of the water temperature became negative correlations in three areas. This result was not statistically significant. However, the sardine resource is a change trend inphase with Chlorophyll-a of Oyashio and Perturbed area. The resource is changed by the opposite phase with the water temperature. The correlation coefficient is low. It is guessed that the water temperature rise negatively influences the sardine resource from the result. Moreover, it is presumed that the decrease in Chlorophyll-a of Oyashio and Perturbed area also decreases the sardine resource. The sardine is inhabited in a cold ocean. The water temperature rise negatively affects growing environment (MCSST). Additionally, it is guessed that food environment (Chlorophyll-a) is bad. 


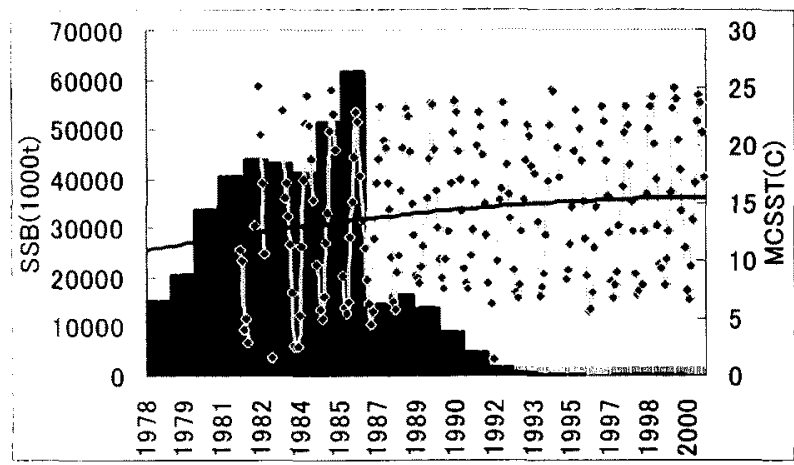

Fig. 11 MCSST and sardine resources (SSB). Perturbed area.

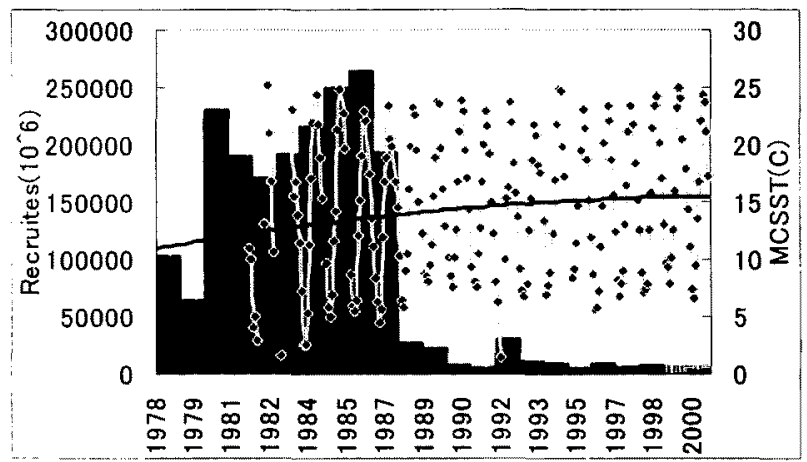

Fig. 12 MCSST and sardine resources (recruits). Perturbed area.

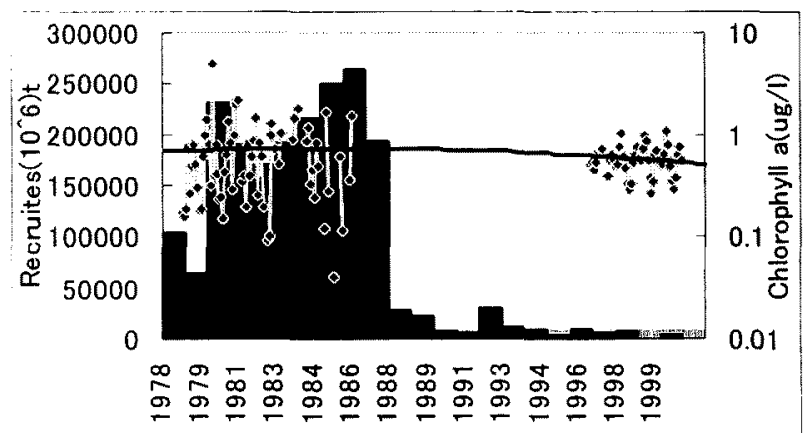

Fig. 13 Chlorophyll-a and sardine resources (SSB). Perturbed area.

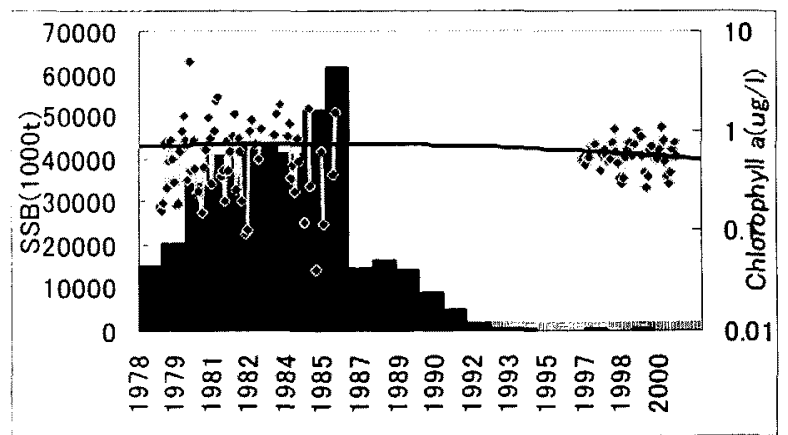

Fig. 14 Chlorophyll-a and sardine resources (recruits). Perturbed area.

\section{SUMMRY AND DISCUSSION}

Three water masses' long-term change trends were calculated according to the satellite data until $1978-2000$. In three water masses, the water temperature was raising trends. On the other hand, it was a decrease trend in Oyasho and Perturbed area as for Chlorophyll-a. In the comparison between resource (Recruitment, SSB) and an oceanic environment, it was suggested that Chlorophyll-a influence from the water temperature. However, the correlation coefficient is not low, and a statistically significant result. This shows that the resource change is not easily decided in three water masses' oceanic environments alone. It is necessary to elucidate the resource change in consideration of water mass's position and a spatial feature. Using the characteristic of the satellite more effectively in the future will advance the research.

\section{ACKNOWLEDGMENTS}

We appreciate to Dr. Fukushima's support about SeaBAM data set and SeaWiFS data. We also appreciate to Dr. Yatsu and Dr. Nishida for their helpful advice in the fisheries data analysis.

\section{REFERENCES}

1. Y.Watanabe and .Wada. Stock fluctuation and ecological changes of the Japanese sardine.1998;Koseisya-Koseikaku pp9-103.

2. Jorge V, Kelly P. and Kay K NOAANASA AVHRR Oceans Pathfinder Sea Surface Temperature Data Set User's Reference Manual.1998. NASA/JPL Publication D-14070.

3. Campbell, J.W., J.M. Blaisdell, and M. Darzi, 1995: Level-3 SeaWiFS Data Products: Spatial and Temporal Binning Algorithms. NASA Tech. Memo. 104566, Vol. 32, S.B. Hooker, E.R. Firestone, and J.G. Acker, Eds., NASA Goddard Space Flight Center, Greenbelt, Maryland.

4. Wada, T. and L. D. Jacobson. Regimes and stock-rectuitment relationships in Japanese sardine (Sardinops melanostictus), 1951-1995. 1998. Can. J. Fish. Aquat. Sci. 55:2455. 2463. 